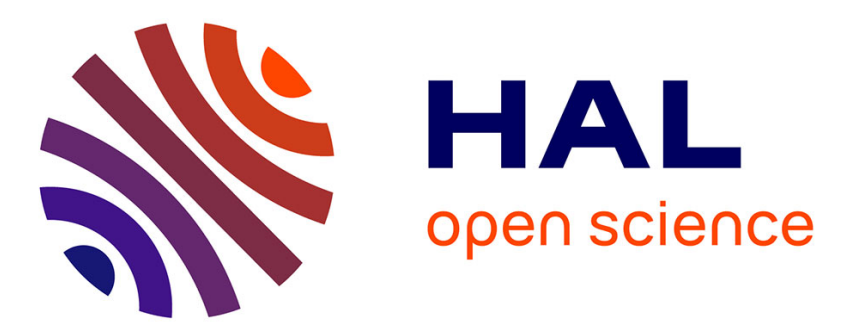

\title{
A comparison of alternative delivery structures in a dual sourcing environment $\left(* * \mathrm{FILE}^{* *}\right)$
}

Christoph H. Glock

\section{To cite this version:}

Christoph H. Glock. A comparison of alternative delivery structures in a dual sourcing environment (**FILE**). International Journal of Production Research, 2011, pp.1. 10.1080/00207543.2011.592160 . hal-00724182

\section{HAL Id: hal-00724182 \\ https://hal.science/hal-00724182}

Submitted on 19 Aug 2012

HAL is a multi-disciplinary open access archive for the deposit and dissemination of scientific research documents, whether they are published or not. The documents may come from teaching and research institutions in France or abroad, or from public or private research centers.
L'archive ouverte pluridisciplinaire HAL, est destinée au dépôt et à la diffusion de documents scientifiques de niveau recherche, publiés ou non, émanant des établissements d'enseignement et de recherche français ou étrangers, des laboratoires publics ou privés. 


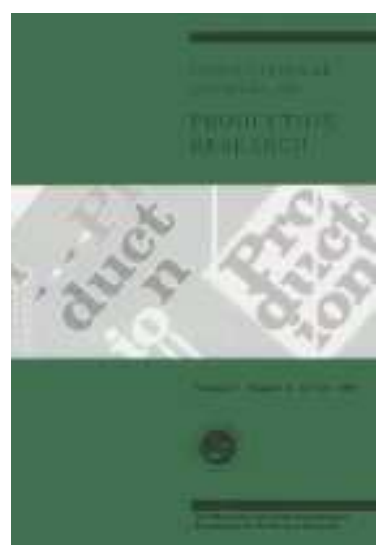

\section{A comparison of alternative delivery structures in a dual sourcing environment ( $* *$ FILE**)}

\begin{tabular}{|r|l|}
\hline Journal: & International Journal of Production Research \\
\hline Manuscript ID: & TPRS-2010-IJPR-1191.R2 \\
\hline Manuscript Type: & Original Manuscript \\
\hline $\begin{array}{r}\text { Date Submitted by the } \\
\text { Author: }\end{array}$ & 30 -Mar-2011 \\
\hline Complete List of Authors: & $\begin{array}{l}\text { Glock, Christoph; University of Wuerzburg, Chair of Business } \\
\text { Management and Industrial Management }\end{array}$ \\
\hline Keywords: & $\begin{array}{l}\text { BATCH SIZING, INVENTORY CONTROL, INVENTORY MANAGEMENT, } \\
\text { LOT SIZING, LOT SPLITTING, SUPPLY CHAIN MANAGEMENT }\end{array}$ \\
\hline Keywords (user): & Delivery structure \\
\hline
\end{tabular}

\section{SCHOLARONE}

Manuscripts 
A comparison of alternative delivery structures in a dual sourcing environment

\author{
Christoph H. Glock \\ Chair of Business Management and Industrial Management \\ University of Würzburg \\ Sanderring 2 \\ 97070 Würzburg \\ Germany \\ Tel.: ++499313182408 \\ Fax: ++49931312405 \\ E-Mail: christoph.glock@uni-wuerzburg.de
}

\begin{abstract}
This paper studies the flow of material between two vendors and a buyer and develops alternative delivery structures with the intention of minimising total system costs. The proposed delivery structures employ alternative design features and give varying degrees of flexibility to the system as to the emergence of inventory and the allocation of inventory among both stages of the supply chain. The delivery structures are compared in a numerical study and it is shown that an increasing degree of flexibility in the delivery structure always leads to lower total system costs. Further, contextual factors that influence relative performance advantages of the structures are identified.
\end{abstract}

Keywords: dual sourcing; integrated inventory; delivery structure; supply chain management; buyer-vendor-relationships 


\section{Introduction}

Global competition and increasingly demanding customers have induced many companies to outsource more and more activities that were previously performed in-house (Monczka et al. 2005; Wee et al. 2010). The strategic importance of a company's supplier (vendor) base is thus enhanced as the value a company creates for its customers is more and more dependent on external sources (Dyer 1996; Caniëls and Roeleveld 2009). As a consequence, the traditional armslength relationship with vendors is replaced by more cooperative ties, and vendors are more frequently involved in internal decision-making processes as well (see e.g. Jayaram 2008).

The importance of effectively managing the relationship between a buyer and its vendors is reflected by the vast amount of articles that have been published in this area. Prior research on the coordination of ordering and production decisions in supply chains can roughly be divided into three different research streams: The first stream of research focuses on the development of lot size- and delivery-policies that minimise the total costs of the system under study and thus enhance the competitive position of the supply chain as a whole. As this stream of research is of special importance for this study, the corresponding models are reviewed in detail in section 2. The second stream of research studies investment decisions in the supply chain and analyses how supply chain partners can enhance the efficiency of the chain by modifying some of the model parameters. Affisco et al. (2002), Liu and Cetinkaya (2007) and Huang et al. (2011), for example, studied the impact of reduced setup costs at the vendor on the performance of the supply chain, while Woo et al. (2001), Zhang et al. (2007) and Lin (2009), among others, focused on the reduction of the buyer's ordering cost. It is obvious that lower costs per setup (order) result in smaller lot sizes and more frequent production runs (orders), which reduces inventory carrying costs and brings the supply chain closer to just-in-time deliveries. Other authors, such as Pan and Yang (2002), Ouyang et al. (2004) and Hoque and Goyal (2006) considered integrated inventory models with stochastic demand and assumed that lead time may be reduced at a crashing cost. If lead time is shortened, the risk of incurring a stockout during lead time decreases, which leads to a lower safety stock, fewer backorders and lower inventory carrying costs. A fourth model parameter that was frequently assumed to be subject to control is product quality. Affisco et al. (2002) and Ouyang (2007), for instance, studied a supply chain where the fraction of defective items resulting from a production process may be reduced if an investment is made. Other authors, such as Comeaux and Sarker (2005) or Ben-Daya and Noman (2008) assumed a constant rate of defectives, but supposed that the vendor or buyer may adopt different inspection policies to identify defective 
items in a lot to prevent them from entering another production process or being sold. Closely related to this stream of research are works that study how companies should adapt to changes in the environment, such as decreasing demand (see e.g. Yang et al. 2008) or a decreasing price level (see e.g. Yu et al. In Press) or product deterioration (see e.g. Yang and Wee 2000). The third research stream finally developed coordination mechanisms that balance the interests of buyer and vendor and thus help to assure both contract formation and contract fulfilment. In this context, many authors assumed that the buyer is the dominant party in the supply chain and studied different types of discounts the vendor may use for inducing the buyer to change its ordering policy. Lal and Staelin (1984) and Dada and Srikanth (1987), for example, considered a supply chain with a single vendor and a single buyer and used a pricing policy with multiple price breaks and a price that decreases monotonically in the order quantity. Other authors, such as Kohli and Park (1994) and Sucky (2005), studied the coordination of a buyer-vendor supply chain as a bargaining problem and showed that the discount scheme which is implemented determines which party benefits from the cost savings that occur as a result of cooperation. Viswanathan and Wang (2003) studied quantity and volume discounts, whereas Chen et al. (2001) analysed a discount schedule based on the annual sales volume, the order quantity, and the order frequency combined with a fixed transfer payment. Prior research indicated that especially in case where demand is price-sensitive and the vendor faces multiple heterogeneous customers, complex coordination schemes, such as the one proposed by Chen et al. (2001), are necessary to coordinate the system. For further works on integrated inventory models, the reader is referred to Ben-Daya et al. (2008) and Sarmah et al. (2006).

One major drawback of the existing literature is that few inventory models explicitly analyse the impact of the delivery structure, i.e. the timing and size of deliveries from the vendors to the buyer, on the total costs of the system. This is insufficient inasmuch as the structure of the vendors' deliveries influences inventory build-up at both the vendors and the buyer, wherefore its control may reduce the total costs of the system. To close this gap, this paper presents and compares alternative delivery structures for the case of a single buyer sourcing a single product from two vendors. The intention of the paper is to show how the sequence and timing of deliveries may influence the cost position of buyer and vendor and provide practitioners with a heuristic planning tool that helps to coordinate buyer-vendor-relationships in practical scenarios.

The remainder of the paper is organised as follows: the next section gives an overview of delivery structures that are commonly discussed in the literature and defines six alternative de- 
livery structures which are analysed in formal models in section 3. Section 4 presents the results of a numerical study and section 5 concludes the article.

\section{Delivery structures in buyer-vendor-relationships}

The coordination of buyer-vendor-relationships has frequently been analysed in the past. One of the first papers that focused explicitly on the total costs of a buyer-vendor-system is due to Banerjee (1986), who studied a single buyer sourcing a product from a single vendor with the intention to minimise total system costs. The author assumed an integer number of setups at both parties, which results in an identical order and production lot size. As a consequence, the vendor produces exactly the order quantity of the buyer in each production cycle and ships the entire lot to the buyer directly after its completion. The model was modified by Goyal (1988), who assumed that the lot size of the vendor equals an integer multiple of the buyer's order quantity. Thus, the vendor may aggregate several of the buyer's orders to a single production lot, which, in turn, is successively shipped to the buyer. This delivery policy is especially beneficial in cases where the vendor's setup costs exceed the buyer's order costs and the opposite pertains for the inventory carrying charges.

While Banerjee and Goyal assumed that the whole production lot must be finished before shipments can be made from this lot, it may be beneficial to transport partial shipments to the buyer. This leads to an earlier start of the consumption cycle and reduces inventory in the system, at the expense of higher delivery costs. This aspect was analysed by Lu (1995), among others, who assumed that the vendor delivers an integral number of equal-sized shipments per production cycle to the buyer, and who considered a fixed delivery cost for each delivery. Alternative policies were provided by Chatterjee and Ravi (1991) and Goyal (1995), who admitted partial shipments as well, but analysed batches that increase by a fixed factor being equal to the production rate $P$ divided by the demand rate $D$.

Further models that addressed the question of how to transport the vendor's production lot to the buyer are due to Hill (1997, 1999), Goyal and Nebebe (2000), and Hill and Omar (2006). An optimal solution for the single-vendor-single-buyer case was developed by Hill (1999) and Hill and Omar (2006), who showed that an optimal delivery structure includes shipments increasing in size according to a geometric series with $\lambda=P / D$ followed by equal-sized shipments. In this context, geometrically increasing shipments guarantee that the system inventory at the beginning of a production cycle is minimised, whereas equal-sized shipments assure that the buyer's inventory is not increased more than necessary. An alternative solution pro- 
cedure for the models developed by Hill (1999) and Hill and Omar (2006) is proposed by Hoque (2009).

If more than one vendor is considered in an inventory model, the question of how the deliveries of the vendors to the buyer should be organised arises. Kim and Goyal (2009) differentiate between two alternative ways of forwarding batch shipments to the buyer: In case of lumpy deliveries, the vendors deliver simultaneously to the buyer, whereas in case of phased deliveries, the vendors deliver alternately. Park et al. (2006) considered a system with multiple vendors and a single buyer and assumed that the vendors may aggregate several of the buyer's orders to a single production lot. In this model, the vendors deliver simultaneously to the buyer, wherefore the buyer has to store the whole order quantity at the beginning of each order cycle. Jaber and Goyal (2009) considered the case of a four-level supply chain with multiple buyers, a single vendor and multiple tier-1 and tier- 2 vendors. The authors assumed that each vendor may choose a production cycle that equals an integer multiple of the order cycle of the following stage. Again, vendors were assumed to deliver simultaneously. Kim and Goyal (2009) studied a system with a single buyer and multiple vendors and considered both lumpy and phased deliveries. Since they assumed that only complete lots are forwarded to the buyer, the vendors deliver in such a way that the shipments reach the buyer when its inventory position approaches zero. Further models that investigate the case of a phased delivery can be found in Rosenblatt et al. (1998), Kheljani et al. (2009), Sarker and Diponegoro (2009) and Glock (2010).

Other authors (see for example Kelle and Silver (1990), Sculli and Shum (1990), Guo and Ganeshan (1995), and Ganeshan (1999)) considered multi-vendor-single-buyer-models with stochastic lead times. The authors assumed that the vendors initiate production simultaneously and that the point of delivery depends on the realisation of the vendors' lead times. Thus, if two vendors realise the same lead time, they deliver simultaneously to the buyer, whereas in case of different lead times, their deliveries occur successively.

The literature review illustrates that prior research has concentrated on analysing two alternative delivery structures: simultaneous (lumpy) and successive (phased) deliveries. A major limitation of the existing research is that authors assumed that only complete lots are shipped from the vendors to the buyer, resulting in two simple delivery structures that can easily be analysed. If the vendors, in contrast, decide to deliver a production lot in multiple batch shipments to the buyer, more alternatives for structuring the deliveries exist. Figure 1 illustrates six alternative delivery structures that have, to the best of the author's knowledge, not been studied in prior research and that will therefore be analysed in the following. The delivery 
structures differ with respect to the number of batch shipments, delay times and delivery dates and thus give the system different options to influence how much inventory emerges and where inventory is kept in the system. The characteristics of the delivery structures shown in figure 1 can be summarised as follows:

- In case a), we assume that both vendors initiate production directly after receipt of the order and deliver simultaneously to the buyer, which corresponds to the case of a lumpy delivery introduced by Kim and Goyal (2009). This scenario may describe situations where the buyer aims to minimise handling effort in the receiving department or where it is necessary to receive deliveries simultaneously due to technical reasons.

- In case b), we consider a scenario where both vendors initiate production at the same time, but where it is not necessary to deliver batches simultaneously. As a result, the delivery frequency at the vendors may be different.

- In case c), the second vendor initiates production $U$ time units after vendor 1 . Thus, the system gains additional flexibility, since simultaneous deliveries may no longer be avoided only by changing the length of the production cycles of the vendors, but also by shifting the production cycle of one of the vendors into the future.

- Case d) considers a situation where both vendors deliver simultaneously after $t$ time units. However, the stock level at the vendors is not necessarily depleted to zero with each delivery. In contrast to case a), the majority of inventory is thus no longer automatically transferred to the buyer, which may help to take advantage of lower inventory carrying costs at the vendors.

- In case e), we assume that the vendors initiate production simultaneously and transport a batch to the buyer every $t_{i}$ time units. Again, the vendors do not have to deliver at the same time.

- Case f) refers to a scenario where the second vendor initiates production $U$ time units after the first vendor, and where each vendor delivers a batch after $t_{i}$ time units to the buyer. If $U$ is chosen large enough, the vendors deliver their respective lots successively, which corresponds to the case of a phased delivery described by Kim and Goyal (2009). Case f) provides the highest flexibility of all delivery structures analysed in this paper.

Figure 1 


\section{Model formulation}

\subsection{Model assumptions and definitions}

In the following, we study a system where a single buyer purchases a single product from two vendors. The scenario discussed in this paper is representative for a variety of industries, for example the machine-building industry, where large manufacturers often maintain relationships to two or more vendors as individual vendors are not always able to satisfy the customer's demand. This is especially the case when products are needed whose production process does not require expensive tools, which is the case for turned or milled parts, for example, wherefore qualifying more than one supplier is not prohibitively expensive. Apart from the assumptions already stated, we assumed the following in developing the proposed model:

1. All parameters are deterministic and constant over time.

2. The capacity of a single vendor is not sufficient to satisfy the demand at the buyer. Thus, we consider the case where the buyer either faces small vendors, or where the vendors have only reserved a limited fraction of their capacity for the buyer due to the dual sourcing-agreement (cf. Rosenblatt et al. (1998), p. S97, for a practical example). We explicitly focus on this situation to exclude the trivial case where the deliveries of the vendors do not overlap (Problems which are associated with overlapping deliveries will be described below). However, our model may be easily extended to consider the simpler case, where the production rates of the vendors exceed the demand rate of the buyer and no overlapping occurs, as well.

3. The cumulative capacity of both vendors exceeds the demand of the buyer. Consequently, the demand at the buyer may be satisfied without interruption.

4. It is technically possible to deliver partial shipments to the buyer before the entire production lot is completed.

5. Shortages are not allowed.

Model assumptions which are only valid for the respective delivery structures will be described at the appropriate places below.

\section{Model Parameters:}

$$
\begin{aligned}
& A=\text { order cost [\$/order] } \\
& D=\text { demand rate [units/time] } \\
& h^{(b)}=\text { unit inventory carrying charges at the buyer [\$/unit/time] } \\
& h_{i}^{\left({ }^{()}\right.}=\text {unit inventory carrying charges at vendor } i \text { [\$/unit/time] }
\end{aligned}
$$


$P_{i}=$ production rate at vendor $i$ [units/time]

$S_{i}=$ setup cost at vendor $i[\$ /$ setup $]$

$T_{i}=$ delivery cost at vendor $i$ [\$/delivery]

\section{Decision Variables:}

$m_{i}=$ number of batch shipments in a production cycle at vendor $i$ with $m_{i} \geq 1$ and $m_{i}$ being an integer

$t_{i}=$ time between two successive deliveries of vendor $i$ [time]

$U=$ time difference between the production start of vendor $i$ and $j$ [time]

$q_{i}=$ production lot size of vendor $i$ with $q_{i}>0 \forall i$ [units]

\section{Definitions:}

$I^{\text {con }}=$ inventory during the consumption phase [units·time]

$I^{m i n}=$ minimum inventory [units.time]

$I^{\text {prod }}=$ inventory during the production phase [units.time]

$T C^{(S)}=$ total costs of the system [\$/time]

$T C^{(b)}=$ total costs of the buyer [\$/time]

$T C_{i}^{(v)}=$ total costs of vendor $i[\$ /$ time $]$

$\max [a, b]=$ the maximum value of $a$ and $b$

$\min [a, b]=$ the minimum value of $a$ and $b$

consumption cycle $=$ the time necessary to consume an order of size $\sum_{i=1}^{2} q_{i}$ at the buyer

production cycle $\quad=$ the time necessary to complete a lot of size $q_{i}$ at vendor $i$

production phase $=$ the time between the start of production at the first vendor and the end of production at the last vendor

\subsection{Models where the majority of inventory is transferred to the buyer}

\section{Model a)}

We first consider the case where both vendors deliver simultaneously to the buyer (cf. part a) of Figure 1 for the corresponding inventory time plots). Since both vendors initiate production directly after receipt of the order, the time between two deliveries is identical for both vendors. Thus, it follows that 
$\frac{q_{i}}{m_{i} P_{i}}=\frac{q_{j}}{m_{j} P_{j}}$ or $q_{i}=\frac{P_{i}}{P_{j}} q_{j}$ with $m_{i}=m_{j}$

Note that the production time of a batch must not exceed the consumption time of a batch of each of the vendors to assure an uninterrupted supply of materials to the buyer. As is shown in appendix A, this condition is always satisfied for the present case.

The vendors' inventory follows the typical EOQ-pattern, wherefore the time weighted inventory at vendor $i$ may be expressed as

$$
\frac{q_{i}^{2}}{2 m_{i} P_{i}}
$$

The total costs of vendor $i$ can be derived if the time weighted inventory is divided by the cycle time and multiplied with the unit inventory carrying charges per unit of time $h_{i}^{(v)}$, and if the setup and delivery costs are considered in addition:

$$
T C_{i}^{(v)}=\frac{q_{i} D h_{i}^{(v)}}{2 m_{i} \sum_{j=1}^{2} P_{j}}+\left(S_{i}+m_{i} T_{i}\right) \frac{D P_{i}}{q_{i} \sum_{j=1}^{2} P_{j}}
$$

The buyer's inventory, as proposed by Joglekar (1988), consists of the difference between the total system inventory and the inventory at the vendors. The total system inventory, in turn, consists of three components: the minimal inventory, inventory during the production phase, and inventory during the exclusive consumption phase (i.e. the time span where the buyer consumes and none of the vendors produces).

The total system inventory is at its minimum at the time the order is issued. At this point, the buyer has just enough stock to satisfy demand until the first shipment is received, i.e. enough stock to satisfy demand for $q_{i} /\left(m_{i} P_{i}\right)$ time units. The minimal inventory is kept in stock for the whole consumption cycle, i.e. for $\sum_{i=1}^{2} q_{i} / D$ time units. It follows that

$$
I^{\text {min }}=\frac{q_{i} D}{m_{i} P_{i}} \frac{\sum_{j=1}^{2} q_{j}}{D}=\frac{q_{i} \sum_{j=1}^{2} q_{j}}{m_{i} P_{i}}=\frac{q_{i}^{2} \sum_{j=1}^{2} P_{j}}{m_{i} P_{i}^{2}}
$$

During the production phase, which takes $q_{i} / P_{i}$ time units, both vendors produce with their respective production rates. The cumulative, time-weighted production quantity during the production phase equals $\sum_{i=1}^{2} q_{i}^{2} / 2 P_{i}$ units. Concurrently, the buyer consumes with the demand rate $D$, which leads to a cumulative consumption of $\left(q_{i}^{2} D\right) /\left(2 P_{i}^{2}\right)$ units. Inventory during the production phase thus equals

$$
I^{\text {prod }}=\sum_{j=1}^{2} \frac{q_{j}^{2}}{2 P_{j}}-\frac{q_{i}^{2} D}{2 P_{i}^{2}}=\sum_{j=1}^{2} \frac{q_{i}^{2} P_{j}^{2}}{2 P_{j} P_{i}^{2}}-\frac{q_{i}^{2} D}{2 P_{i}^{2}}=\frac{q_{i}^{2}}{2 P_{i}^{2}}\left(\sum_{j=1}^{2} P_{j}-D\right)
$$


After the vendors have delivered their respective last batches to the buyer, the buyer consumes for another $\sum_{j=1}^{2} q_{j} / D-q_{i} / P_{i}$ time units. Inventory in the exclusive consumption phase thus equals

$$
I^{c o n}=\frac{D}{2}\left(\sum_{j=1}^{2} \frac{q_{j}}{D}-\frac{q_{i}}{P_{i}}\right)^{2}=\frac{D}{2}\left(\sum_{j=1}^{2} \frac{q_{i} P_{j}}{D P_{i}}-\frac{q_{i}}{P_{i}}\right)^{2}=\frac{D q_{i}^{2}}{2 P_{i}^{2}}\left(\sum_{j=1}^{2} \frac{P_{j}}{D}-1\right)^{2}
$$

The total time weighted system inventory is now given as the sum of (4), (5), and (6). Inventory at the buyer may be calculated if the inventory at the vendors is subtracted from the total system inventory, which leads to

$$
\frac{q_{i}^{2}}{2 P_{i}^{2}}\left(\sum_{j=1}^{2} \frac{P_{j}\left(m_{i}+1\right)}{m_{i}}-D+D\left(\sum_{j=1}^{2} \frac{P_{j}}{D}-1\right)^{2}\right)
$$

To derive the total costs of the buyer, the time weighted inventory first has to be divided by the cycle time and multiplied with the unit inventory carrying charges per unit of time $h^{(b)}$. Considering order costs in addition leads to:

$$
T C^{(b)}=\frac{q_{i} h^{(b)} D}{2 P_{i} \sum_{j=1}^{2} P_{j}}\left(\sum_{j=1}^{2} \frac{P_{j}\left(m_{i}+1\right)}{m_{i}}-D+D\left(\sum_{j=1}^{2} \frac{P_{j}}{D}-1\right)^{2}\right)+\frac{A D P_{i}}{q_{i} \sum_{j=1}^{2} P_{j}}
$$

The total system costs for model a) are given as the sum of (8) and (3):

$$
\begin{aligned}
T C^{(S)} & =\frac{q_{i} D}{2 \sum_{j=1}^{2} P_{j}}\left(\left(\sum_{j=1}^{2} \frac{P_{j}\left(m_{i}+1\right)}{m_{i}}-D+D\left(\sum_{j=1}^{2} \frac{P_{j}}{D}-1\right)^{2}\right) \frac{h^{(b)}}{P_{i}}+\sum_{j=1}^{2} \frac{h_{j}^{(v)} P_{j}}{m_{i} P_{i}}\right) \\
& +\left(A+\sum_{j=1}^{2}\left(S_{j}+m_{i} T_{j}\right)\right) \frac{D P_{i}}{q_{i} \sum_{j=1}^{2} P_{j}}
\end{aligned}
$$

Since simulation studied indicated that (9) is quasi-convex in both $q_{i}$ and $m_{i}$, an optimal solution for the decision variables can be found with the help of differential calculus. First, (9) is differentiated with respect to $q_{i}$, set equal to zero and solved for $q_{i}$, which gives the optimal lot size for a given shipment frequency. An optimal value for $m_{i}$, in turn, can be found by increasing $m_{i}$ stepwise from 1 until the total costs start to increase. The optimal solution is then given as $m_{i}-1$.

\section{Model b)}

In model b), we relax the assumption that both vendors deliver simultaneously and assume that the production cycles and delivery frequencies at the vendors may be different (cf. part b) 
of Figure 1 for the corresponding inventory time plots). However, we still assume that both vendors initiate production simultaneously.

If we consider the sequence of deliveries first, both vendors initiate production at time $t=0$ and finish a batch after $q_{i} /\left(m_{i} P_{i}\right)$ time units. The time to consume a batch at the buyer equals $q_{i} /\left(m_{i} D\right)$ time units, wherefore, due to $P_{i}<D$, the time to consume a batch is always shorter than its corresponding production time. As a consequence, it is necessary to schedule deliveries in such a way that the first batch of the vendor who delivers second arrives at the latest when the first batch of the vendor who delivers first has been completely used up. Thus, the following condition has to be satisfied to guarantee an uninterrupted supply of materials at the buyer:

$$
\left|\frac{q_{i}}{m_{i} P_{i}}-\frac{q_{j}}{m_{j} P_{j}}\right| \leq\left\{\begin{array}{lll}
\frac{q_{i}}{m_{i} D} & \text { if } & \frac{q_{i}}{m_{i} P_{i}} \leq \frac{q_{j}}{m_{j} P_{j}} \\
\frac{q_{j}}{m_{j} D} & \text { if } & \frac{q_{i}}{m_{i} P_{i}}>\frac{q_{j}}{m_{j} P_{j}}
\end{array}\right.
$$

Further, it is necessary to restrict the maximum production time of a batch to assure that it does not exceed the consumption time of a batch of each of the vendors. Thus, we may formulate the following condition:

$\frac{q_{i}}{m_{i} P_{i}} \leq \sum_{j=1}^{2} \frac{q_{j}}{m_{j} D} \quad \forall i$

Finally, the production phase must not exceed the consumption cycle to avoid shortages at the buyer. Thus, it follows that

$$
\frac{q_{i}}{P_{i}} \leq \sum_{j=1}^{2} \frac{q_{j}}{D} \quad \forall i
$$

The total costs of vendor $i$ correspond to those given in equation (3). The total system inventory, as outlined above, consists of the minimal inventory, inventory during the production phase, and inventory during the exclusive consumption phase. The minimum inventory in the system depends on the lead time of the first batch, which is $\min \left[\frac{q_{i}}{m_{i} P_{i}}, \frac{q_{j}}{m_{j} P_{j}}\right]$ in the present case. Thus, it follows that

$$
I^{\min }=\min \left[\frac{q_{i}}{m_{i} P_{i}}, \frac{q_{j}}{m_{j} P_{j}}\right] D \frac{\sum_{j=1}^{2} q_{j}}{D}=\min \left[\frac{q_{i}}{m_{i} P_{i}}, \frac{q_{j}}{m_{j} P_{j}}\right] \sum_{j=1}^{2} q_{j}
$$

During the production phase, which takes $\max \left[q_{i} / P_{i}, q_{j} / P_{j}\right]$ time units, at least one of the vendors produces. The cumulative production quantity during the production phase equals 


$$
\sum_{i=1}^{2}\left(\frac{q_{i}^{2}}{2 P_{i}}+q_{i}\left(\max \left[\frac{q_{i}}{P_{i}}, \frac{q_{j}}{P_{j}}\right]-\frac{q_{i}}{P_{i}}\right)\right)
$$

The inventory during the production phase can now be calculated if the consumption of the buyer during this time is considered in addition:

$$
I^{\text {prod }}=\max \left[\frac{q_{i}}{P_{i}}, \frac{q_{j}}{P_{j}}\right] \sum_{i=1}^{2} q_{i}-\sum_{i=1}^{2} \frac{q_{i}^{2}}{2 P_{i}}-\frac{D}{2}\left(\max \left[\frac{q_{i}}{P_{i}}, \frac{q_{j}}{P_{j}}\right]\right)^{2}
$$

With reference to equation (6), inventory in the exclusive consumption phase can be calculated as

$$
I^{\text {con }}=\frac{D}{2}\left(\sum_{j=1}^{2} \frac{q_{j}}{D}-\max \left[\frac{q_{i}}{P_{i}}, \frac{q_{j}}{P_{j}}\right]\right)^{2}
$$

The total time weighted system inventory is now given as the sum of (13), (15), and (16). Inventory at the buyer may be calculated if the inventory at the vendors is subtracted from the total system inventory, which leads to

$$
\min \left[\frac{q_{i}}{m_{i} P_{i}}, \frac{q_{j}}{m_{j} P_{j}}\right] \sum_{i=1}^{2} q_{i}+\frac{\left(\sum_{i=1}^{2} q_{i}\right)^{2}}{2 D}-\sum_{i=1}^{2} \frac{q_{i}^{2}\left(m_{i}+1\right)}{2 m_{i} P_{i}}
$$

The total costs of the buyer can now be derived if the time weighted inventory is divided by the cycle time and multiplied with the unit inventory carrying charges per unit of time $h^{(b)}$, and if the order costs are considered in addition:

$$
T C^{(b)}=\left(\min \left[\frac{q_{i}}{m_{i} P_{i}}, \frac{q_{j}}{m_{j} P_{j}}\right] \sum_{i=1}^{2} q_{i}+\frac{\left(\sum_{i=1}^{2} q_{i}\right)^{2}}{2 D}-\sum_{i=1}^{2} \frac{q_{i}^{2}\left(m_{i}+1\right)}{2 m_{i} P_{i}}\right) \frac{h^{(b)} D}{\sum_{i=1}^{2} q_{i}}+A \frac{D}{\sum_{i=1}^{2} q_{i}}
$$

The total system costs for model b) are given as the sum of (3) and (18), whereby (3) has to be summed up over all vendors:

$$
\begin{aligned}
T C^{(S)} & =\left(\left(\min \left[\frac{q_{i}}{m_{i} P_{i}}, \frac{q_{j}}{m_{j} P_{j}}\right] \sum_{i=1}^{2} q_{i}+\frac{\left(\sum_{i=1}^{2} q_{i}\right)^{2}}{2 D}-\sum_{i=1}^{2} \frac{q_{i}^{2}\left(m_{i}+1\right)}{2 m_{i} P_{i}}\right) h^{(b)}+\sum_{i=1}^{2} \frac{q_{i}^{2} h_{i}^{(v)}}{2 m_{i} P_{i}}\right) \frac{D}{\sum_{i=1}^{2} q_{i}} \\
& +\left(A+\sum_{i=1}^{2}\left(S_{i}+m_{i} T_{i}\right)\right) \frac{D}{\sum_{i=1}^{2} q_{i}}
\end{aligned}
$$

Finding an optimal solution for model b) proves to be difficult since the min- and maxoperators in (19) prohibit differential optimisation. However, an (at least locally) optimal solution can be found by applying a steepest descent-method (cf. Gill et al. 1981), which works as follows: First, the solution found for model a) with $m_{i}=m_{j}$ is adopted as a starting solution. 


\section{Model c)}

We now further relax the assumption that both vendors initiate production simultaneously and assume that vendor $j$ starts production $U$ time units after vendor $i$ (cf. part c) of Figure 1 for the corresponding inventory time plots). As explained above, due to $P_{i}<D$, it is necessary to schedule deliveries in such a way that the first batch of the vendor who delivers second arrives at the latest when the first batch of the vendor who delivers first has been completely used up. Thus, condition (10) may be adopted as follows to suit the present problem:

$$
\left|\frac{q_{i}}{m_{i} P_{i}}-\frac{q_{j}}{m_{j} P_{j}}-U\right| \leq\left\{\begin{array}{lll}
\frac{q_{i}}{m_{i} D} & \text { if } & \frac{q_{i}}{m_{i} P_{i}} \leq \frac{q_{j}}{m_{j} P_{j}}+U \\
\frac{q_{j}}{m_{j} D} & \text { if } & \frac{q_{i}}{m_{i} P_{i}}>\frac{q_{j}}{m_{j} P_{j}}+U
\end{array}\right.
$$

Further, as in model b), condition (11) hast to be satisfied in the current case. Finally, condition (12) has to be adopted to assure that the production phase does not exceed the consumption cycle of the buyer:

$$
\max \left[\frac{q_{i}}{P_{i}}, \frac{q_{j}}{P_{j}}+U\right] \leq \sum_{j=1}^{2} \frac{q_{j}}{D}
$$

Since, for a given set of model parameters and decision variables, shifting the production cycle of vendor $j$ into the future has no impact on the inventory of vendor $i$ and $j$, the total costs of vendor $i$ correspond to those given in expression (3).

The total time weighted system inventory may again be derived by considering the minimal inventory, inventory during the production phase, and inventory during the exclusive consumption phase. If we assume that vendor $i$ initiates production first and vendor $j$ second, then the minimum inventory in the system again depends on the lead time of the first batch, which is $\min \left[\frac{q_{i}}{m_{i} P_{i}}, \frac{q_{j}}{m_{j} P_{j}}+U\right]$ in the present case. Thus, it follows that

$$
I^{\min }=\min \left[\frac{q_{i}}{m_{i} P_{i}}, \frac{q_{j}}{m_{j} P_{j}}+U\right] D \frac{\sum_{j=1}^{2} q_{j}}{D}=\min \left[\frac{q_{i}}{m_{i} P_{i}}, \frac{q_{j}}{m_{j} P_{j}}+U\right] \sum_{j=1}^{2} q_{j}
$$


During the production phase, which takes $\max \left[q_{i} / P_{i}, q_{j} / P_{j}+U\right]$ time units, at least one vendor produces. The cumulative production quantity during the production phase equals

$$
\begin{gathered}
\sum_{k=1}^{2}\left(\frac{q_{k}^{2}}{2 P_{k}}+q_{k}\left(\max \left[\frac{q_{i}}{P_{i}}, \frac{q_{j}}{P_{j}}+U\right]-\frac{q_{k}}{P_{k}}-\alpha\right)\right) \\
\text { with } \alpha=\left\{\begin{array}{lll}
0 & \text { if } \quad k=i \\
U & \text { if } & k=j
\end{array}\right.
\end{gathered}
$$

The inventory during the production phase can now be calculated if the consumption of the buyer during this time is considered in addition:

$$
I^{\text {prod }}=\max \left[\frac{q_{i}}{P_{i}}, \frac{q_{j}}{P_{j}}+U\right] \sum_{i=1}^{2} q_{i}-\sum_{i=1}^{2} q_{i} \alpha-\sum_{i=1}^{2} \frac{q_{i}^{2}}{2 P_{i}}-\frac{D}{2}\left(\max \left[\frac{q_{i}}{P_{i}}, \frac{q_{j}}{P_{j}}+U\right]\right)^{2}
$$

Inventory in the exclusive consumption phase can be calculated as

$$
I^{\text {con }}=\frac{D}{2}\left(\sum_{j=1}^{2} \frac{q_{j}}{D}-\max \left[\frac{q_{i}}{P_{i}}, \frac{q_{j}}{P_{j}}+U\right]\right)^{2}
$$

The total time weighted system inventory is now given as the sum of (22), (24), and (25). Inventory at the buyer may be calculated if the inventory at the vendors is subtracted from the total system inventory, which leads to

$$
\min \left[\frac{q_{i}}{m_{i} P_{i}}, \frac{q_{j}}{m_{j} P_{j}}+U\right] \sum_{i=1}^{2} q_{i}-\sum_{i=1}^{2} q_{i} \alpha+\frac{\left(\sum_{i=1}^{2} q_{i}\right)^{2}}{2 D}-\sum_{i=1}^{2} \frac{q_{i}^{2}\left(m_{i}+1\right)}{2 m_{i} P_{i}}
$$

The total costs of the buyer can now be derived if the time weighted inventory is divided by the cycle time and multiplied with the unit inventory carrying charges per unit of time $h^{(b)}$, and if the order costs are considered in addition:

$$
T C^{(b)}=\left(\min \left[\frac{q_{i}}{m_{i} P_{i}}, \frac{q_{j}}{m_{j} P_{j}}+U\right] \sum_{i=1}^{2} q_{i}-\sum_{i=1}^{2} q_{i} \alpha+\frac{\left(\sum_{i=1}^{2} q_{i}\right)^{2}}{2 D}-\sum_{i=1}^{2} \frac{q_{i}^{2}\left(m_{i}+1\right)}{2 m_{i} P_{i}}\right) \frac{h^{(b)} D}{\sum_{i=1}^{2} q_{i}}+A \frac{D}{\sum_{i=1}^{2} q_{i}}(27)
$$

The total system costs for model c) are given as the sum of (3) and (27), whereby (3) has to be summed up over all vendors: 


$$
\begin{aligned}
T C^{(S)} & =\left(\left(\min \left[\frac{q_{i}}{m_{i} P_{i}}, \frac{q_{j}}{m_{j} P_{j}}+U\right] \sum_{i=1}^{2} q_{i}-\sum_{i=1}^{2} q_{i} \alpha+\frac{\left(\sum_{i=1}^{2} q_{i}\right)^{2}}{2 D}-\sum_{i=1}^{2} \frac{q_{i}^{2}\left(m_{i}+1\right)}{2 m_{i} P_{i}}\right) h^{(b)}+\sum_{i=1}^{2} \frac{q_{i}^{2} h_{i}^{(v)}}{2 m_{i} P_{i}}\right) \frac{D}{\sum_{i=1}^{2} q_{i}} \\
& +\left(A+\sum_{i=1}^{2}\left(S_{i}+m_{i} T_{i}\right)\right) \frac{D}{\sum_{i=1}^{2} q_{i}}
\end{aligned}
$$

A good solution for the model may be found by using the procedure developed for model b), which has to be adopted as follows: First, $U$ is set to zero and a starting solution is computed. After one of the shipment frequencies has been varied and solutions for $q_{i}$ and $q_{j}$ have been found, $U$ is increased by a sufficiently small step size, e.g. 0.01 , and new values for $q_{i}$ and $q_{j}$ are calculated. This is repeated until a further increase in $U$ does not lead to a decrease in total system costs, and then the procedure described above is continued. Note that a shift in the production cycle of both vendors has to be tested to find a (locally) optimal solution.

\subsection{Models where the majority of inventory is not necessarily transferred to the buyer}

We now relax the assumption that the majority of inventory is transferred to the buyer and assume that the vendors transport a batch every $t_{i}$ time units to the buyer. In contrast to models a) to c), inventory at the vendors is not necessarily depleted to zero with every shipment.

\section{Model d)}

At first, we concentrate on the case were both vendors are supposed to deliver simultaneously to the buyer, which corresponds to model a) discussed in section 3.2. In this case, the time between two deliveries of a vendor, $t_{i}$, is identical for both vendors. In contrast to model a), $t_{i}$ is not restricted to $q_{i} /\left(m_{i} P_{\mathrm{i}}\right)$, but may adopt every value equal to or larger to $q_{i} /\left(m_{i} P_{\mathrm{i}}\right)$ that guarantees that the demand at the buyer may be satisfied without interruption. Thus, we conclude that

$$
\frac{q_{i}}{m_{i} P_{i}} \leq t_{i} \leq \frac{\sum_{j=1}^{2} q_{j}}{D m_{i}} \quad \forall i
$$

The other constraints formulated for models b) and c), which assure that the batches arrive on time and that the production phase does not exceed the consumption cycle, are not necessary here since both vendors deliver simultaneously and $\sum P_{i}>D$ holds.

As is shown in appendix $\mathrm{B}$, the time weighted inventory at vendor $i$ may be expressed as: 


$$
\frac{q_{i}^{2}}{2 P_{i}}+q_{i}\left(m_{i} t_{i}-\frac{q_{i}}{P_{i}}\right)-\frac{q_{i} t_{i}\left(m_{i}-1\right)}{2}=\frac{q_{i} t_{i}\left(m_{i}+1\right)}{2}-\frac{q_{i}^{2}}{2 P_{i}}
$$

The total costs of vendor $i$ may thus be calculated as:

$$
T C_{i}^{(v)}=\left(\left(\frac{q_{i} t_{i}\left(m_{i}+1\right)}{2}-\frac{q_{i}^{2}}{2 P_{i}}\right) h_{i}^{(v)}+S_{i}+m_{i} T_{i}\right) \frac{D}{\sum_{i=1}^{2} q_{i}}
$$

The total system inventory can be derived as described above. The minimum inventory depends on the lead time of the first batch, which is $t_{i}$ for both vendors. Thus, it follows that

$$
I^{\min }=D t_{i} \frac{\sum_{j=1}^{2} q_{j}}{D}=t_{i} \sum_{j=1}^{2} q_{j}
$$

During the production phase, which takes $q_{i} / P_{i}$ time units, both vendors produce with their respective production rates. The cumulative production quantity during the production phase equals $\sum_{i=1}^{2} q_{i}^{2} /\left(2 P_{i}\right)$ units. Further, after production is interrupted at the vendors, the last batch remains in stock until $t=m_{i} t_{i}$. Thus, an additional stock in the amount of $q_{i}\left(m_{i} t_{i}-q_{i} / P\right)$ has to be considered at the vendors. Concurrently, the buyer consumes with the demand rate $D$, which leads to a cumulative consumption of $D\left(m_{i} t_{i}\right)^{2} / 2$ units. Inventory during the production phase thus equals

$$
I^{\text {prod }}=\sum_{j=1}^{2} \frac{q_{j}^{2}}{2 P_{j}}+\sum_{j=1}^{2} q_{j}\left(m_{i} t_{i}-\frac{q_{j}}{P_{j}}\right)-\frac{D\left(m_{i} t_{i}\right)^{2}}{2}=\sum_{i=1}^{2} q_{i} m_{i} t_{i}-\sum_{j=1}^{2} \frac{q_{j}^{2}}{2 P_{j}}-\frac{D\left(m_{i} t_{i}\right)^{2}}{2}
$$

After the vendors have delivered their last batches to the buyer, the buyer consumes exclusively for another $\sum_{i=1}^{2} q_{i} / D-m_{i} t_{i}$ time units. Inventory in the exclusive consumption phase thus equals

$$
I^{c o n}=\frac{D}{2}\left(\frac{\sum_{j=1}^{2} q_{j}}{D}-m_{i} t_{i}\right)^{2}
$$

The total time weighted system inventory is now given as the sum of (32), (33), and (34). Inventory at the buyer may be calculated if the inventory at the vendors is subtracted from the total system inventory, which leads to

$$
\frac{\left(\sum_{j=1}^{2} q_{j}\right)^{2}}{2 D}+\frac{t_{i}\left(1-m_{i}\right) \sum_{j=1}^{2} q_{j}}{2}
$$

The total costs of the buyer can now be derived if the time weighted inventory is divided by the cycle time and multiplied with the unit inventory carrying charges per unit of time $h^{(b)}$, and if the order costs are considered in addition: 


$$
T C^{(b)}=\left(\frac{\left(\sum_{j=1}^{2} q_{j}\right)^{2}}{2 D}+\frac{t_{i}\left(1-m_{i}\right) \sum_{j=1}^{2} q_{j}}{2}\right) \frac{h^{(b)} D}{\sum_{i=1}^{2} q_{i}}+A \frac{D}{\sum_{i=1}^{2} q_{i}}
$$

The total system costs for model d) are given as the sum of (31) and (36), whereby (31) has to be summed up over all vendors:

$$
\begin{aligned}
T C^{(S)} & =\left(\left(\frac{\left(\sum_{j=1}^{2} q_{j}\right)^{2}}{2 D}+\frac{t_{i}\left(1-m_{i}\right) \sum_{j=1}^{2} q_{j}}{2}\right) h^{(b)}+\sum_{j=1}^{2}\left(\frac{q_{j} t_{i}\left(m_{j}+1\right)}{2}-\frac{q_{j}^{2}}{2 P_{j}}\right) h_{j}^{(v)}\right) \frac{D}{\sum_{i=1}^{2} q_{i}}+ \\
& +\left(A+\sum_{i=1}^{2}\left(S_{i}+m_{i} T_{i}\right)\right) \frac{D}{\sum_{i=1}^{2} q_{i}}
\end{aligned}
$$

Due to the complexity of (37), convexity in the decision variables cannot be proved. However, since model d) reduces to model a) for $t_{i}=q_{i} /\left(m_{i} P_{i}\right)$, a near-optimal solution can be found by adopting the solution procedure developed for model a). First, $t_{i}$ is set equal to zero and a starting solution is computed. Second, $t_{i}$ is increased by a sufficiently small step size, e.g. 0.01, and new values for $q_{i}$ and $q_{j}$ are calculated. $t_{i}$ is then increased further until an increase does not lead to a reduction in total system costs anymore. The procedure described above is then continued until an optimal solution has been found.

\section{Model e)}

We now again relax the assumption that both vendors deliver simultaneously and assume that the production cycles and delivery frequencies at the vendors may be different (cf. part e) of Figure 1 for the corresponding inventory time plots), but that both vendors initiate production simultaneously. Again, the following condition has to be satisfied to guarantee an uninterrupted supply of materials at the buyer:

$\left|t_{i}-t_{j}\right| \leq\left\{\begin{array}{lll}\frac{q_{i}}{m_{i} D} & \text { if } & t_{i} \leq t_{j} \\ \frac{q_{j}}{m_{j} D} & \text { if } & t_{i}>t_{j}\end{array}\right.$

Further, conditions (11) and (12) have to be adopted:

$$
\begin{aligned}
& \frac{q_{i}}{m_{i} P_{i}} \leq t_{i} \leq \sum_{j=1}^{2} \frac{q_{j}}{m_{j} D} \quad \forall i \\
& m_{i} t_{i} \leq \sum_{j=1}^{2} \frac{q_{j}}{D} \quad \forall i
\end{aligned}
$$


With the exception that $m_{i}$ and $m_{j}$ as well as $t_{i}$ and $t_{j}$, are not identical, inventory at the vendors corresponds to the one derived in appendix B. As a consequence, the total cost function of vendor $i$ is given by expression (31).

The total time weighted system inventory can be derived by calculating the minimum inventory, inventory during the production phase, and inventory in the exclusive consumption phase. The lead time of the first batch of vendor $i$ equals $t_{i}$, wherefore the minimum inventory is given as

$$
I^{\min }=D \min \left[t_{i}, t_{j}\right] \frac{\sum_{j=1}^{2} q_{j}}{D}=\min \left[t_{i}, t_{j}\right] \sum_{j=1}^{2} q_{j}
$$

Inventory during the production phase corresponds to the one given in (15), with the exception that it now takes $\max \left[m_{i} t_{i}, m_{j} t_{j}\right]$ time units until the last batch is delivered to the buyer. Thus, it follows that

$$
I^{\text {prod }}=\max \left[m_{i} t_{i}, m_{j} t_{j}\right] \sum_{i=1}^{2} q_{i}-\sum_{i=1}^{2} \frac{q_{i}^{2}}{2 P_{i}}-\frac{D}{2}\left(\max \left[m_{i} t_{i}, m_{j} t_{j}\right]\right)^{2}
$$

Inventory in the exclusive consumption phase can be calculated as

$$
I^{c o n}=\frac{D}{2}\left(\sum_{j=1}^{2} \frac{q_{j}}{D}-\max \left[m_{i} t_{i}, m_{j} t_{j}\right]\right)^{2}
$$

The total time weighted system inventory is now given as the sum of (41), (42), and (43). Inventory at the buyer may be calculated if the inventory at the vendors is subtracted from the total system inventory, which leads to

$$
\min \left[t_{i}, t_{j}\right] \sum_{i=1}^{2} q_{i}+\frac{\left(\sum_{i=1}^{2} q_{i}\right)^{2}}{2 D}-\frac{1}{2} \sum_{i=1}^{2} q_{i} t_{i}\left(m_{i}+1\right)
$$

The total costs of the buyer can now be derived if the time weighted inventory is divided by the cycle time and multiplied with the unit inventory carrying charges per unit of time $h^{(b)}$, and if the order costs are considered in addition:

$$
T C^{(b)}=\left(\min \left[t_{i}, t_{j}\right] \sum_{i=1}^{2} q_{i}+\frac{\left(\sum_{i=1}^{2} q_{i}\right)^{2}}{2 D}-\frac{1}{2} \sum_{i=1}^{2} q_{i} t_{i}\left(m_{i}+1\right)\right) \frac{h^{(b)} D}{\sum_{i=1}^{2} q_{i}}+A \frac{D}{\sum_{i=1}^{2} q_{i}}
$$

The total system costs for model b) are given as the sum of (31) and (45), whereby (31) has to be summed up over all vendors: 


\section{Modelf)}

Finally, we consider the case where vendor $j$ initiates production $U$ time units after vendor $i$ and where both vendors deliver equal-sized batch shipments to the buyer after $t_{i}$ time units. To assure that the first batch of the vendor that delivers second reaches the buyer in time, the following condition has to be satisfied:

$$
\left|t_{i}-t_{j}-U\right| \leq\left\{\begin{array}{lll}
\frac{q_{i}}{m_{i} D} & \text { if } & t_{i} \leq t_{j}+U \\
\frac{q_{j}}{m_{j} D} & \text { if } & t_{i}>t_{j}+U
\end{array}\right.
$$

Further, (39) and the following condition have to hold:

$$
\max \left[m_{i} t_{i}, m_{j} t_{j}+U\right] \leq \sum_{j=1}^{2} \frac{q_{j}}{D}
$$

As pointed out above, shifting the production cycle of vendor $j$ into the future has no impact on the inventory of vendor $i$ and $j$. Consequently, the total costs of vendor $i$ correspond to those given in expression (31).

The total time weighted system inventory may again be derived by considering the minimal inventory, inventory during the production phase, and inventory during the exclusive consumption phase. If we assume that vendor $i$ initiates production first and vendor $j$ second, then 
the minimum inventory in the system again depends on the lead time of the first batch, which is $\min \left[t_{i}, t_{j}+U\right]$ in the present case. Thus, it follows that

$$
I^{\min }=\min \left[t_{i}, t_{j}+U\right] D \frac{\sum_{j=1}^{2} q_{j}}{D}=\min \left[t_{i}, t_{j}+U\right] \sum_{j=1}^{2} q_{j}
$$

Inventory during the production phase equals the one given in (24) with the exception that it now takes $\max \left[m_{i} t_{i}, m_{j} t_{j}+U\right]$ time units until the last batch is delivered to the buyer. Thus, it follows that

$$
I^{\text {prod }}=\max \left[m_{i} t_{i}, m_{j} t_{j}+U\right] \sum_{i=1}^{2} q_{i}-\sum_{i=1}^{2} q_{i} \alpha-\sum_{i=1}^{2} \frac{q_{i}^{2}}{2 P_{i}}-\frac{D}{2}\left(\max \left[m_{i} t_{i}, m_{j} t_{j}+U\right]\right)^{2}
$$

Inventory in the exclusive consumption phase can be calculated as

$$
I^{\text {con }}=\frac{D}{2}\left(\sum_{j=1}^{2} \frac{q_{j}}{D}-\max \left[m_{i} t_{i}, m_{j} t_{j}+U\right]\right)^{2}
$$

The total time weighted system inventory is now given as the sum of (49) to (51). Inventory at the buyer may be calculated if the inventory at the vendors is subtracted from the total system inventory, which leads to

$$
\min \left[t_{i}, t_{j}+U\right] \sum_{i=1}^{2} q_{i}-\sum_{i=1}^{2} q_{i} \alpha+\frac{\left(\sum_{i=1}^{2} q_{i}\right)^{2}}{2 D}-\sum_{i=1}^{2} \frac{q_{i} t_{i}\left(m_{i}+1\right)}{2}
$$

The total costs of the buyer can now be derived if the time weighted inventory is divided by the cycle time and multiplied with the unit inventory carrying charges per unit of time $h^{(b)}$, and if the order costs are considered in addition:

$$
T C^{(b)}=\left(\min \left[t_{i}, t_{j}+U\right] \sum_{i=1}^{2} q_{i}-\sum_{i=1}^{2} q_{i} \alpha+\frac{\left(\sum_{i=1}^{2} q_{i}\right)^{2}}{2 D}-\sum_{i=1}^{2} \frac{q_{i} t_{i}\left(m_{i}+1\right)}{2}\right) \frac{h^{(b)} D}{\sum_{i=1}^{2} q_{i}}+A \frac{D}{\sum_{i=1}^{2} q_{i}}
$$

The total system costs for model f) are given as the sum of (31) and (53), whereby (31) has to be summed up over all vendors:

$$
\begin{aligned}
T C^{(S)} & =\left(\left(\min \left[t_{i}, t_{j}+U\right] \sum_{i=1}^{2} q_{i}-\sum_{i=1}^{2} q_{i} \alpha+\frac{\left(\sum_{i=1}^{2} q_{i}\right)^{2}}{2 D}-\sum_{i=1}^{2} \frac{q_{i} t_{i}\left(m_{i}+1\right)}{2}\right) h^{(b)}\right. \\
& \left.+\sum_{i=1}^{2}\left(\frac{q_{i} t_{i}\left(m_{i}+1\right)}{2}-\frac{q_{i}^{2}}{2 P_{i}}\right) h_{i}^{(v)}\right) \frac{D}{\sum_{i=1}^{2} q_{i}}+\left(A+\sum_{i=1}^{2}\left(S_{i}+m_{i} T_{i}\right)\right) \frac{D}{\sum_{i=1}^{2} q_{i}}
\end{aligned}
$$

A good solution for the decision variables can be found by using the procedure developed for model e), which has to be adopted as follows: First, $U$ is set to zero and a starting solution is 


\section{Figure 2}

computed. After one of the shipment frequencies has been varied and solutions for $q_{i} / q_{j}$ and $t_{i} / t_{j}$ have been found, $U$ is increased by a sufficiently small step size, e.g. 0.01 , and new values for $q_{i} / q_{j}$ and $t_{i} / t_{j}$ are calculated. This is repeated until a further increase in $U$ does not lead to a decrease in total system costs, and then the procedure described above is continued. Note that a shift in the production cycle of both vendors has to be tested to find a (locally) optimal solution.

\section{Numerical Studies}

To illustrate the impact of the delivery structures developed in section 3 on the total costs of the system, we considered the following numerical example: $D=1000, P_{1}=800, P_{2}=600, A$ $=50, S_{1}=300, S_{2}=250, T_{1}=40, T_{2}=60$ and $h^{(b)}=2$. Further, we assumed that $h_{1}{ }^{(v)}=0.5 \varepsilon h^{(b)}$ and $h_{2}{ }^{(v)}=0.6 \varepsilon h^{(b)}$ and varied $\varepsilon$ within the range [0,3] to study the impact of different ratios of $h^{(b)}$ and $h_{i}^{(v)}$ on the efficiency of the delivery structures. It follows that $h_{1}{ }^{(v)}<h^{(b)}$ for $\varepsilon<2$ and $h_{2}{ }^{(v)}<h^{(b)}$ for $\varepsilon<5 / 3$, wherefore we may expect that models d) to f) perform better as compared to models a) to c) for lower values of $\varepsilon$, since keeping the majority of inventory at the buyer is less beneficial from a systems perspective if the costs for holding inventory are lower at the vendors. The total system costs of the respective models for different values of $\varepsilon$ are shown in Figure 2.

\footnotetext{
As can be seen, models d), e) and f) led to the lowest total costs for $\varepsilon=0$. In this hypothetical case, keeping inventory at the vendors is free of cost, wherefore delaying the shipment of completed batches (and thus keeping the majority of inventory at the vendors) reduces total system cost. As $\varepsilon$ increases, the relative advantage of models d) to f) is reduced. While model f) always results in the lowest total costs, the total costs of model d) increase stronger as compared to the other models as $\varepsilon$ adopts higher values. For $\varepsilon=1.4$, it is not beneficial anymore to keep the majority of inventory at the vendors, wherefore batches are shipped to the buyer directly after their completion. This leads to identical results for models a) and d). To gain further insights into the behaviour of our model, we conducted a simulation study wherein the performance of the delivery structures for 1.000 randomly generated data sets
} 
was analysed. To generate the random parameter values, the ranges depicted in table 1 were employed.

\section{Table 1}

Table 2 contains a descriptive analysis of the results derived in the simulation study. The first two columns of the table describe the models that were compared in the corresponding rows of the table, while columns three to five indicate how often the first model outperformed the second or led to the same or led to inferior results. The last column illustrates the average savings in total system costs that could be achieved by preferring model $i$ to model $j$.

The delivery structures proposed in sections 3.2 and 3.3 differ from each other with respect to three design features: the use of unequal delivery frequencies at the vendors, the use of a delay in the initiation of the production process at one of the vendors, and the use of a delay in the shipment of completed batches. As can be seen in table 2, models that combined several of the design features constantly led to equal or better results than models that used less of the same features. For example, model c), which combines unequal delivery frequencies with a delay in the initiation of the production process of one of the vendors, never led to worse results than models a) or b), which uses only one or none of these features. Model f), which combines all design features, consequently dominated all other delivery structures, and led on average to $34.51 \%$ lower total costs than model a), for example. We may thus conclude that it is better from a systems perspective to consider all three design features introduced in this paper in designing a delivery structure than concentrating on a selection of them.

\section{Table 2}

As to the question of which of the design features leads to the highest cost reduction, our study indicates that using unequal delivery frequencies at the vendors leads to the highest reduction in total costs. As can be seen in table 2, model b), which uses different delivery cycles at the vendors, outperforms model a), which assumes that delivery frequencies are equal, on average by $32.81 \%$, while model e), which combines unequal delivery frequencies with a de- 
lay in the shipment time at the vendors, leads on average to $33.07 \%$ lower total costs than model a). In contrast, comparing models a) and d) indicates that introducing a delay in the shipment time at the vendors leads to a lower improvement in total costs. This is due to the fact that delaying a batch shipment only influences whether inventory is kept at the vendors or at the buyers (and consequently inventory carrying costs), while allowing delivery frequencies to adopt different values helps to economise on delivery costs as well. Similar results may be derived from table 2 for a delay in the initiation of the production process at one of the vendors. We may thus conclude that in case companies prefer to adopt only one of the design features proposed in this paper, for example to keep the delivery structures simple, unequal delivery frequencies should be used at the vendors, since they may be expected to have the highest impact on total system cost. However, we note that this is not valid for all possible parameter settings, since model d) was able to outperform models b) and c) in some cases. Therefore, a careful analysis of the situation under study is always a better approach than using this rule of thumb.

To analyse which model parameters are most important for performance differences of the models, we conducted regression analyses wherein we related the ratio of the total system costs of each possible pair of models to the problem parameters. To keep the length of this paper within reasonable limits, we refrain from presenting all results of our study, but only discuss the most important results here:

- As can be seen in table 2, model d) outperforms model b) in some cases. The results of our regression analysis indicates that the ratio $\left.T C^{(S)}{ }_{d} / T C^{(S)}{ }_{b}\right)$ is negatively related to the ratio $D /\left(P_{1}+P_{2}\right)($ Beta $=-0.710$, Sig. $=0.000)$ and positively related to $h^{(b)}($ Beta $=0.114$, Sig. $=0.000)$. Obviously, delaying the shipments of the vendors is superior to using unequal shipment frequencies especially in scenarios where the sum of the production rates $P_{1}$ and $P_{2}$ is close to the demand rate $D$ and $h^{(b)}$ is low. This result is surprising, since model d) enables the system to keep the majority of inventory at the vendors and thus reduces inventory at the buyer, which is not possible in model b). However, model b) reduces the overall inventory in the system due to unequal delivery frequencies at the vendors, which obviously balances this effect. If, in contrast, the sum of the production rates is close to the demand rate, the production process at the vendors is only interrupted for a short time span after the lot is completed, and high inventory has to be kept in the system. In such a case, enabling the system to shift inventory from the buyer to the vendors is obviously more important than reducing inventory at the vendors by implementing unequal 
delivery frequencies. The same relationships could be identified for performance differences between models d) and c).

- Table 2) further indicates that model e) may outperform model c), i.e. that a delay in the shipment of completed batches can be better than a delay in the initiation of the production process at one of the vendors and vice versa. In our regression analysis, we found a negative relationship between the ratio $\left.\left.T C^{(S)}{ }_{e}\right) / T C^{(S)}{ }_{c}\right)$ and the ratio $D /\left(P_{1}+P_{2}\right)$ (Beta = 0.128, Sig. = 0.000). This confirms the findings introduced above and emphasises that a delay in the shipment of completed batches is especially beneficial in case production and demand in the system are relatively synchronised.

- As to the question of which vendor should be subject to a delay in the initiation of the production cycle, our study indicates that it is beneficial to delay the production cycle of the vendor with the higher production rate and the higher carrying charges (i.e. we found a positive and significant relationship between the ratios $P_{i} / P_{j}$ and $h_{i}^{(v)} / h_{j}{ }^{(v)}$ and the delay of the production cycle of vendor $i$ ). This obviously serves the purpose to reduce inventory at the vendors, since the vendor with the higher production rate needs less time to produce a given lot size than the slower vendor. Thus, a delay of the production cycle of the slower vendor would increase the time the faster vendor needs to bridge with the first batch delivery (i.e. a longer time span between the first and the second delivery at the buyer, which results in a larger batch size at the faster vendor), which increases system costs. As a consequence, it is better to delay the production cycle of the faster vendor and/or the vendor with the higher inventory carrying costs.

\section{Conclusion}

This paper developed and compared six alternative delivery structures for buyer-vendorrelationships that differ by their use of three design features, i.e. unequal delivery frequencies at the vendors, a delay in the initiation of the production process at one of the vendors, and a delay in the shipment of completed batches. Numerical studies indicated that implementing a flexible delivery structure which employs all three design features always leads to the lowest total system costs. Further, our studies showed that using unequal delivery frequencies at the vendors led to the highest improvement in total costs as compared to the other design features in many cases, wherefore we recommend this feature as the preferred design instrument in organising the delivery of vendors. Finally, our studies indicated that delaying the shipment of completed batches at the vendors, as compared to the other design features, is especially beneficial in cases where production and demand in the system are almost synchronised. 


\section{Appendix A}

To assure an uninterrupted supply of materials, the following condition must hold:

$$
\frac{q_{i}}{m_{i} P_{i}} \leq \sum_{j=1}^{2} \frac{q_{j}}{m_{i} D}
$$

This is equivalent to

$$
\frac{q_{i}}{m_{i} P_{i}} \leq \sum_{j=1}^{2} \frac{q_{i} P_{j}}{m_{i} D P_{i}}=\frac{q_{i}}{m_{i} D P_{i}} \sum_{j=1}^{2} P_{j}
$$

Simplification leads to

$$
D \leq \sum_{j=1}^{2} P_{j}
$$

According to the assumptions made in developing the model, this condition is always satisfied.

\section{Appendix B}

As proposed by Joglekar (1988), the time weighted inventory of vendor $i$ can be calculated by computing the cumulative production of the vendor in a production cycle and subtracting the 
cumulative quantity shipped to the buyer. Figure 3 illustrates the cumulative quantity produced and shipped for a vendor exemplarily.

Figure 3

The cumulative production represents the sum of the triangle ABC and the rectangle BCED. The triangle $\mathrm{ABC}$ is given as:

$\frac{q_{i}^{2}}{2 P_{i}}$

The quadrangle BCED equals:

$q_{i}\left(m_{i} t_{i}-\frac{q_{i}}{P_{i}}\right)$

The cumulative quantity shipped equals the gray step-ladder and can thus be calculated as:

$$
\frac{q_{i} t_{i}}{m_{i}}\left(m_{i}-1\right)+\frac{q_{i} t_{i}}{m_{i}}\left(m_{i}-2\right)+\ldots+\frac{q_{i} t_{i}}{m_{i}}=\frac{q_{i} t_{i}}{m_{i}} \sum_{i=1}^{m_{i}}\left(m_{i}-i\right)=\frac{q_{i} t_{i}\left(m_{i}-1\right)}{2}
$$

The time weighted inventory thus equals:

$$
\frac{q_{i}^{2}}{2 P_{i}}+q_{i}\left(m_{i} t_{i}-\frac{q_{i}}{P_{i}}\right)-\frac{q_{i} t_{i}\left(m_{i}-1\right)}{2}
$$

\section{References}

Affisco, J.F., Paknejad, M.J., and Nasri, F., 2002. Quality improvement and setup reduction in the joint economic lot size model. European Journal of Operational Research, 142 (3), 497-508.

Banerjee, A., 1986. A joint economic-lot-size model for purchaser and vendor. Decision Sciences, 17 (3), 292-311.

Ben-Daya, M., Darwish, M., and Ertogral, K., 2008. The joint economic lot sizing problem: Review and extensions. European Journal of Operational Research, 185 (2), 726-742.

Ben-Daya, M. and Noman, S.M., 2008. Integrated inventory and inspection policies for stochastic demand. European Journal of Operational Research, 185 (1), 159-169.

Caniëls, M.C.J. and Roeleveld, A., 2009. Power and dependence perspectives on outsourcing decisions. European Management Journal, 27 (6), 402-417.

Chatterjee, A.K and Ravi R., 1991. Joint economic lot-size model with delivery in subbatches. Operations Research, 28 (2), 118-124. 
Chen, F., Federgruen, A., and Zheng, Y.-S., 2001. Coordination Mechanisms for a Distribution System with One Supplier and Multiple Retailers. Management Science, 47 (5), 693 708.

Comeaux, E.J. and Sarker, B.R., 2005. Joint Optimization of Process Improvement Investments for Supplier-Buyer Cooperative Commerce. Journal of the Operational Research Society, 56 (11), 1310-1324.

Dada, M. and Srikanth, K.N., 1987. Pricing policies for quantity discounts. Management Science, 33 (10), 1247-1252.

Dyer, J.H., 1996. Specialized Supplier Networks as a Source of Competitive Advantage: Evidence from the Auto Industry. Strategic Management Journal, 17 (4), 271-291.

Ganeshan, R., 1999. Managing Supply Chain Inventories: A Multiple Retailer, One Warehouse, Multiple Supplier Model. International Journal of Production Economics, 59 (13), 341-354.

Gill, P.E., Murray, W., and Wright, M.H., 1981. Practical Optimization. London: Academic Press.

Glock, C.H., 2010b. A multiple-vendor single-buyer integrated inventory model with a variable number of vendors. Computers \& Industrial Engineering, 60 (1), 173-182.

Goyal, S.K., 1988. A joint economic-lot-size model for purchaser and vendor: a comment. Decision Sciences, 19 (1), 236-241.

Goyal, S.K., 1995. A one-vendor multi-buyer integrated inventory model: A comment. European Journal of Operational Research, 82 (1), 209-210.

Goyal, S.K. and Nebebe F., 2000. Determination of economic production-shipment policy for a single-vendor-single-buyer system. European Journal of Operational Research, 121 (1), 175-178.

Guo, Y. and Ganeshan, R., 1995. Are More Suppliers Better? Journal of the Operational Research Society, 46 (7), 892-895.Hill, R.M., 1997. The single-vendor single-buyer integrated production-inventory model with a generalised policy. European Journal of Operational Research, 97 (3), 493-499.

Hill, R.M., 1999. The optimal production and shipment policy for the single-vendor singlebuyer integrated production-inventory problem. International Journal of Production Research, 37 (11), 2463-2475.

Hill, R.M. and Omar, M., 2006. Another look at the single-vendor single-buyer integrated production-inventory model. International Journal of Production Research, 44 (4), 791800. 
Hoque, M.A., 2009. An alternative optimal solution technique for a single-vendor singlebuyer integrated production inventory model. International Journal of Production Research, 47 (15), 4063-4076.

Hoque, M.A. and Goyal, S.K., 2006. A heuristic solution procedure for an integrated inventory system under controllable lead-time with equal or unequal sized batch shipments between a vendor and a buyer. International Journal of Production Economics, 102 (2), 217-225.

Huang, C.-K., Cheng, T.L., Kao, T.C., and Goyal, S.K., 2011. An integrated inventory model involving manufacturing setup cost reduction in compound Poisson process. International Journal of Production Research, 49 (4), 1219-1228.

Jaber, M.Y. and Goyal, S.K., 2009. A basic model for co-ordinating a four-level supply chain of a product with a vendor, multiple buyers and tier-1 and tier-2 suppliers. International Journal of Production Research, 47 (13), 3691-3704.

Jayaram, J., 2008. Supplier involvement in new product development projects: dimensionality and contingency effects. International Journal of Production Research, 46 (13), 37173735 .

Joglekar, P.N., 1988. Comments on 'A quantity discount pricing model to increase vendor profits'. Management Science, 34 (11), 1391-1398.

Kelle, P. and Silver, E.A., 1990. Decreasing expected shortages through order splitting. Engineering Costs and Production Economics, 19 (1-3), 351-357.

Kheljani, J.G., Ghodsypour, S.H., and O’Brien, C., 2009. Optimizing whole supply chain benefit versus buyer's benefit through supplier selection. International Journal of Production Economics, 121 (2), 482-493.

Kim, T. and Goyal, S.K., 2009. A consolidated delivery policy of multiple suppliers for a single buyer. International Journal of Procurement Management, 2 (3), 267-287.

Kohli, R. and Park, H., 1994. Coordinating Buyer-seller Transactions Across Multiple Products. Management Science, 40 (9), 1145-1150.

Lal, R. and Staelin, R., 1984. An approach for developing an optimal discount pricing policy. Management Science, 30 (12), 1524-1539

Lin, Y.-L., 2009. An integrated vendor-buyer inventory model with backorder price discount and effective investment to reduce ordering cost. Computers \& Industrial Engineering, 56 (4), 1597-1606. 
Liu, X. and Cetinkaya, S., 2007. A note on "quality improvement and setup reduction in the joint economic lot size model". European Journal of Operational Research, 182 (1), 194204.

Lu, L., 1995. A one-vendor multi-buyer integrated inventory model. European Journal of Operational Research, 81 (2), 312-323.

Minner, S., 2003. Multiple-supplier inventory models in supply chain management: A review. International Journal of Production Economics, 81-82 (1), 265-279.

Monczka, R.M., Trent, R.J., and Handfield, R.B., 2005. Purchasing and Supply Chain Management. 3rd ed. Mason, OK: Thomson/South Western.

Ouyang, L.-Y., Wu, K.-S., and Ho, C.-H., 2004. Integrated vendor-buyer cooperative models with stochastic demand in controllable lead time. International Journal of Production Economics, 92 (3), 255-266.

Ouyang, L.-Y., Wu, K.-S., and Ho, C.-H., 2007. An integrated vendor-buyer inventory model with quality improvement and lead time reduction. European Journal of Operational Research, 108 (1-2), 349-358.

Pan, J.C.-H. and Yang, J.-S., 2002. A study of an integrated inventory with controllable lead time. International Journal of Production Research, 40 (5), 1263-1273.

Park, S.S., Kim, T., and Hong, Y., 2006. Production allocation and shipment policies in a multiple-manufacturer-single-retailer supply chain. International Journal of Systems Science, 37 (3), 163-171.

Rosenblatt, M.J., Herer, Y.T., and Hefter, I., 1998. Note. An Acquisition Policy for a Single Item Multi-Supplier System. Management Science, 44 (11), S96-S100.

Sarmah, S.P., Acharya, D., and Goyal, S.K., 2006. Buyer vendor coordination models in supply chain management. European Journal of Operational Research, 175 (1), 1-15.

Sarker, B.R. and Diponegoro, A., 2009. Optimal production plans and shipment schedules in a supply-chain system with multiple suppliers and multiple buyers. European Journal of Operational Research, 194 (3), 753-773.

Sculli, D. and Shum, Y.W., 1990. Analysis of a Continuous Review Stock-control Model with Multiple Suppliers. Journal of the Operational Research Society, 41 (9), 873-877.

Sucky, E., 2005. Inventory management in supply chains: A bargaining problem. International Journal of Production Economics, 93-94 (1), 253-262.

Viswanathan, S. and Wang, Q, 2003. Discount pricing decisions in distribution channels with price-sensitive demand. European Journal of Operational Research, 149 (3), 571-587 
Wee, H.-M., Peng, S.-Y., and Wee, K.-P., 2010. Modelling of outsourcing decisions in global supply chains. An empirical study on supplier management performance with different outsourcing strategies. International Journal of Production Research, 48 (7), 2081-2094.

Woo, Y.Y., Hsu, S.-L., and Wu, S., 2001. An integrated inventory model for a single vendor and multiple buyers with ordering cost reduction. International Journal of Production Economics, 73 (3), 203-215.

Yang, P.-C. and Wee, H.-M., 2000. Economic ordering policy of deteriorated item for vendor and buyer: an integrated approach. Production Planning \& Control, 11 (5), 474-480.

Yang, P.-C., Wee, H.-M., and Hsu, P.-H., 2008. Collaborative vendor-buyer system with declining market. Computers \& Industrial Engineering, 54 (1), 128-139.

Yu, J., Mungan, D., and Sarker, B. R., In Press. An Integrated Multi-Stage Supply Chain Model Under an Infinite Planning Horizon and Continuous Price Decrease. Computers \& Industrial Engineering, doi:10.1016/j.cie.2011.03.002.

Zhang, T., Liang, L., Yu, Y., and Yu, Y., 2007. An integrated vendor-managed inventory model for a two-echelon system with order cost reduction. International Journal of Production Economics, 109 (1-2), 241-253.

\section{Captions for Figures and Tables}

Figure 1: Delivery structures studied in this paper

Figure 2: Total costs of the delivery structures for different values of $\varepsilon$

Figure 3: Cumulative quantity produced and shipped at a vendor

Table 1: Range of permitted parameter values in the simulation study

Table 2: Comparison of the performance of the delivery structures studied in this paper 


\begin{tabular}{lcccccc}
\hline Parameter & $\boldsymbol{D}$ & $\boldsymbol{P}_{\boldsymbol{i}}$ & $\boldsymbol{A}$ & $\boldsymbol{S}_{\boldsymbol{i}}$ & $\boldsymbol{T}_{\boldsymbol{i}}$ & $\boldsymbol{h}^{(\boldsymbol{b})}, \boldsymbol{h}_{i}^{(\boldsymbol{v})}$ \\
\hline Domain & $100 ; 1000$ & $D / 2+1 ; D-1$ & $20 ; 200$ & $40 ; 500$ & $10 ; 100$ & $1 ; 10$ \\
\hline
\end{tabular}

Table 1

\begin{tabular}{|c|c|c|c|c|c|}
\hline Model $i$ & Model $j$ & $\begin{array}{c}\# \\
T C_{i}^{(S)} \\
<T C_{j}^{(S)}\end{array}$ & $\begin{array}{c}\# \\
T C_{i}^{(S)}=T C_{j}^{(S)}\end{array}$ & $\begin{array}{c}\# \\
T C_{i}^{(S)}>T C_{j}^{(S)}\end{array}$ & Sav. $T C^{(S)}$ \\
\hline Model b) & Model a) & $100 \%$ & $0 \%$ & $0 \%$ & $32.81 \%$ \\
\hline \multirow[t]{2}{*}{ Model c) } & Model a) & $100 \%$ & $0 \%$ & $0 \%$ & $34.20 \%$ \\
\hline & Model b) & $82.1 \%$ & $17.9 \%$ & $0 \%$ & $2.20 \%$ \\
\hline \multirow[t]{3}{*}{ Model d) } & Model a) & $26.7 \%$ & $73.3 \%$ & $0 \%$ & $2.55 \%$ \\
\hline & Model b) & $2.0 \%$ & $0 \%$ & $98.0 \%$ & $-53.5 \%$ \\
\hline & Model c) & $1.0 \%$ & $0 \%$ & $99.0 \%$ & $-57.71 \%$ \\
\hline \multirow[t]{4}{*}{ Model e) } & Model a) & $100 \%$ & $0 \%$ & $0 \%$ & $33.07 \%$ \\
\hline & Model b) & $17.4 \%$ & $82.6 \%$ & $0 \%$ & $0.45 \%$ \\
\hline & Model c) & $25.0 \%$ & $0 \%$ & $75.0 \%$ & $-2.1 \%$ \\
\hline & Model d) & $98.7 \%$ & $1.3 \%$ & $0 \%$ & $31.16 \%$ \\
\hline \multirow[t]{5}{*}{ Model f) } & Model a) & $100 \%$ & $0 \%$ & $0 \%$ & $34.51 \%$ \\
\hline & Model b) & $87.0 \%$ & $13.0 \%$ & $0 \%$ & $2.67 \%$ \\
\hline & Model c) & $34.7 \%$ & $65.3 \%$ & $0 \%$ & $0.62 \%$ \\
\hline & Model d) & $100 \%$ & $0 \%$ & $0 \%$ & $32.67 \%$ \\
\hline & Model e) & $89.1 \%$ & $10.9 \%$ & $0 \%$ & $7.57 \%$ \\
\hline
\end{tabular}

Table 2 


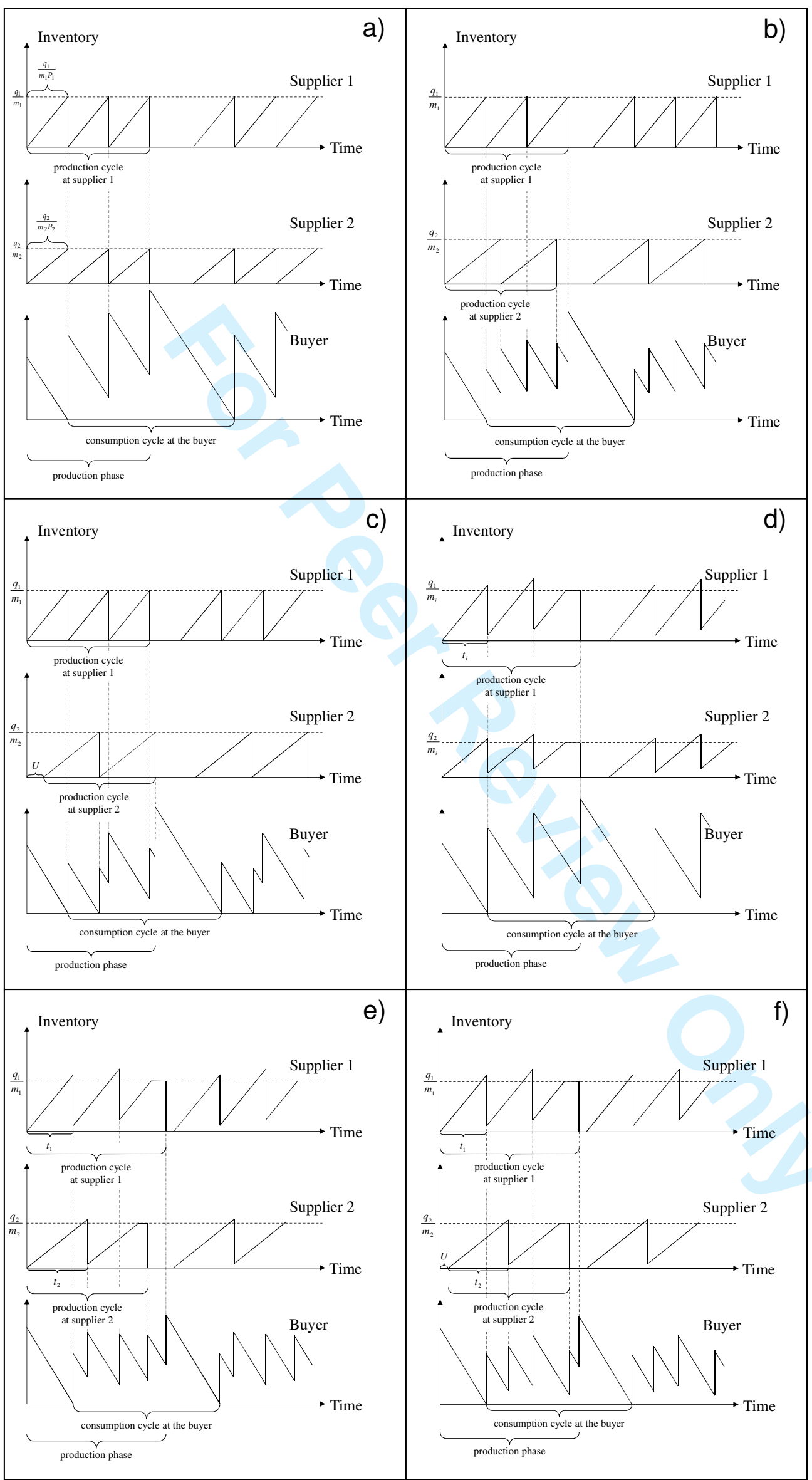

Figure 1: Delivery structures studied in this paper 


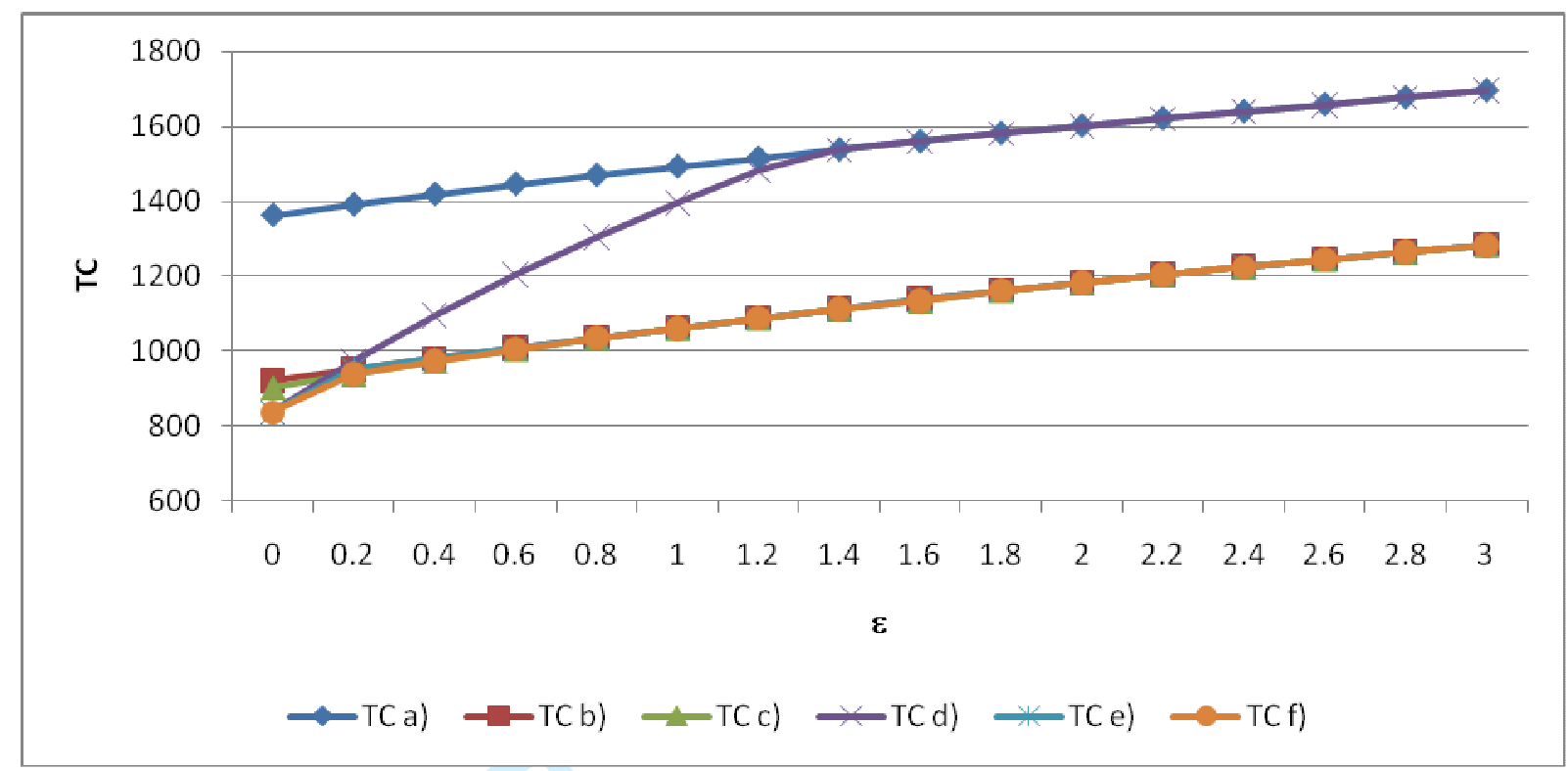

Figure 2: Total costs of the delivery structures for different values of $\varepsilon$ 


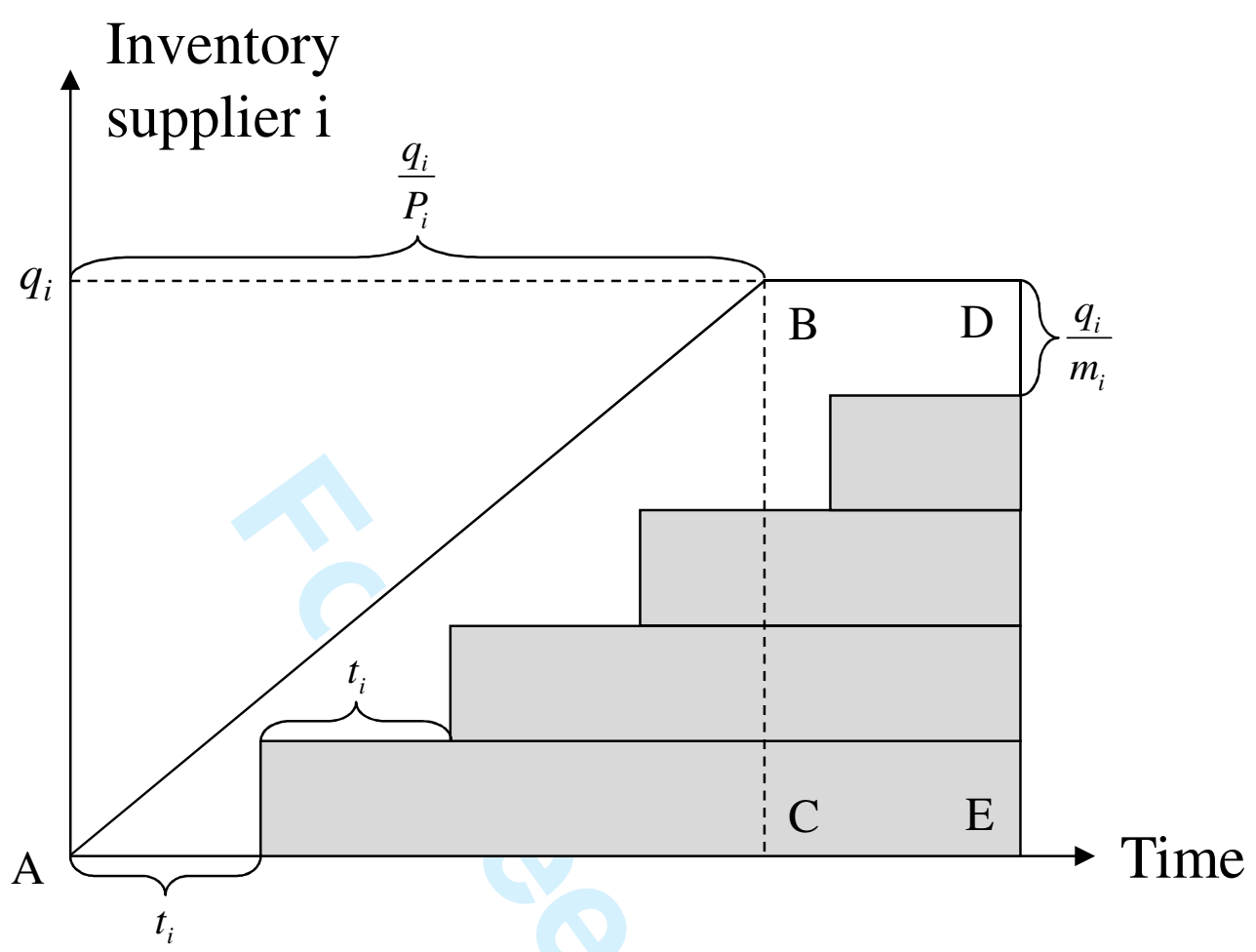

Figure 3:Cumulative quantity produced and shipped at a vendor 